\title{
Detection of macrolide resistant Mycoplasma pneumoniae in England, September 2014 to September 2015
}

RJ Brown ${ }^{12}$, L Macfarlane-Smith ${ }^{3}$, S Phillips ${ }^{1}$, VJ Chalker ${ }^{1}$

1. Bacteriology Reference Department, Public Health England (PHE), London, United Kingdom

2. Cardiff University School of Medicine, Department of Child Health, University Hospital of Wales, Cardiff, United Kingdom

3. Department of Microbiology, Leeds General Infirmary, Leeds, United Kingdom

Correspondence: Victoria J Chalker (Vicki.Chalker@phe.gov.uk)

Citation style for this article:

Brown R, Macfarlane-Smith L, Phillips S, Chalker V. Detection of macrolide resistant Mycoplasma pneumoniae in England, September 2014 to September 2015 . Euro Surveill. 2015;20(48):pii=30078. DOI: http://dx.doi.org/10.2807/1560-7917.ES.2015.20.48.30078

Article submitted on 17 November 2015 / accepted on 03 December 2015 / published on 02 July 2015

Mycoplasma pneumoniae infection can cause pneumonia, particularly in children. Global increase in macrolide-resistant $M$. pneumoniae is of concern due to limited therapeutic options. We describe the detection of macrolide resistance-conferring mutations in $9.3 \%$ of 43 clinical specimens where M. pneumoniae was detected in England and Wales from September 2014-September 2015. This study aims to impact by highlighting the presence of macrolide resistance in M. pneumoniae positive patients, promoting increased clinical vigilance.

Here we report the detection of mutations associated with macrolide resistance in $M$. pneumoniae-positive specimens from four patients with pneumonia in Englandin the periodSeptember 2014 to September 2015. Prior to 2014, in the United Kingdom seven cases of macrolide-resistant $M$. pneumoniae infections were reported between 2008 and 2011, mainly from Scotland $[1,2]$.

\section{Macrolide resistance determination}

The Bacteriology Reference Department, Public Health England (PHE), London, receives specimens from England and Wales for M. pneumoniae testing and confirmatory testing. Here we detected $M$. pneumoniae by qPCR in 60 clinical specimens from 60 patients (Cambridge, Leeds, London, Manchester, Nottingham and Oxford) that were submitted to PHE between 1 September 2014 and 1 September 2015. DNA extractions from specimens, where $M$. pneumoniae was detected, were screened for point mutations known to confer macrolide resistance. Mutations in domain $\mathrm{V}$ of the $23 \mathrm{~S}$ rRNA were detected by a modified version of the method described by Li et al., 2009 [3], wherein the entire region of interest is amplified and sequenced as one product. Primers used were as follows: forward primer 5'-ATCTCTTGACTGTCTCGGC-3' and reverse primer 5'-TACAACTGGAGCATAAGAGGTG-3'.

Of the 60 specimens, 17 (28.3\%; 95\% confidence interval $(\mathrm{Cl})$ : $18.4^{--40.8)}$ contained insufficient DNA to determine macrolide resistance-conferring mutations. Of the remaining 43 specimens mutations in the $23 \mathrm{~S}$ rRNA known to confer macrolide resistance were found in four ( $9.3 \% ; 95 \% \mathrm{Cl}: 3.1-22.2)$. Of these 43 specimens, 32 were from a single city in England, Leeds, and a single specimen among these was positive for the mutation, $3.1 \%(95 \% \mathrm{Cl}: 0.01-17.1)$. The cases identified with point mutations known to confer macrolide-resistant $M$. pneumoniae were in two women and two men, respectively, aged $>15$ to $<65$ years old. Three were hospitalised with pneumonia (Table) with no known connection between patients.

Interestingly, two of the macrolide-resistant cases were patients that had recently arrived from the United States (exact timeline unknown); of which one had received clarithromycin whilst undergoing treatment in the UK. The origins of the infecting $M$. pneumoniae strains in these two cases may have been external to England and Wales. The other two cases were from separate cities in England. All macrolide resistanceconferring mutations were A2058G (Escherichia coli numbering) point mutation in the $23 \mathrm{~S}$ rRNA.

\section{Background}

Mycoplasma pneumoniae can be isolated from patients with lower respiratory tract infection, including pneumonia, and has also been associated with prolonged persistent cough and exacerbation of asthma [4]. $M$. pneumoniae infections may manifest infrequently as extra-pulmonary sequelae after the onset of or even in the absence of respiratory illness [5]; including encephalitis [6], dermatological manifestations such 
Details of patients with macrolide-resistant Mycoplasma pneumoniae-positive clinical specimens, England and Wales, September 2014-September $2015(n=4)$

\begin{tabular}{|l|c|c|c|c|c|}
\hline Case & Age group (years) & Sample type & Pneumonia & Hospitalised & Macrolide before sampling \\
\hline 1 & $45-65$ & TS & Yes & Yes & Unknown \\
\hline 2 & $15-25$ & BAL & Yes & Yes & Yes \\
\hline 3 & $45-65$ & BAL & Yes & Ynknown; Antibiotics class unknown \\
administered before admission
\end{tabular}

BAL: bronchoalveolar lavage; TS: throat swab.

as Stevens-Johnson syndrome [7], and haemolytic anaemia [8]. Asymptomatic carriage of M. pneumoniae has been documented in nasopharyngeal swabs at low levels in England, e.g. at $0.25 \%$ based on PCR in a 2001 carriage study [9], however, a study from the Netherlands reported a much higher carriage rate (21.2\%) [10]. In England and Wales, M. pneumoniae infection can be found in all age groups, with a higher prevalence in children of school age [9]. In England and Wales, seasonal peaks of infection are detected from December to February each year with epidemics at approximately four-yearly intervals, lasting 12 to 15 months [9]. A large increase in reported $M$. pneumoniae cases was documented in several European countries, including England and Wales, in 2011 [11].

\section{Discussion}

In the past 15 years, a significant increase in macrolideresistant $M$. pneumoniae has been reported globally, of increasing concern and importance to the international community [12]. In Asia, resistance rates of over 90\% have been reported [13], particularly in China, whereas in Europe and North America resistance rates of up to $25 \%$ have been documented $[14,15]$. Macrolideresistant strains of $M$. pneumoniae have not been documented to show cross-resistance to other classes of antibiotics i.e. tetracyclines and fluoroquinolones [16].

Prior to 2014, in the United Kingdom, seven cases of macrolide-resistant $M$. pneumoniae infections were reported between 2008 and 2011, one case in England and Wales and six cases in Scotland $[1,2]$. This is the second report of macrolide-resistant $M$. pneumoniae strains detected in England and Wales, with one case previously documented for a single patient specimen from 2008 [1]. Macrolide resistance in M. pneumoniae has been reported in Scotland at 19\% (6/32) [2], considerably higher than the $9.3 \%$ documented here. This may reflect low sample numbers or sampling differences and it is important to note that the specimens examined for macrolide resistance in Scotland were from patients in whom macrolide resistance was considered most likely based on their clinical presentation or history, being one of the following: repeated specimen positive, remaining symptomatic following antibiotic treatment, admitted to critical care or having an underlying condition.

In this study a high number of samples were from a single city in England and a local epidemic cannot be excluded. There is no requirement for referral of M. pneumoniae-positive specimens to the reference laboratory in England and Wales. Systematic testing and referral of positive specimens does not occur. Therefore regional comparison was not possible. Nonetheless, the focus of this article was to highlight macrolide resistance rather than a specific regional cluster analysis.

Macrolides are currently recommended as the firstline treatment for $M$. pneumoniae infection in the UK [17]. The 2011 British Thoracic Society guidelines for the management of community acquired pneumonia in children and adults suggest empirical macrolide treatment at any age if there is no response to first-line betalactam antibiotics or in the case of very severe disease $[17,18]$. Tetracyclines (minocycline and doxycycline) and fluoroquinolones (levofloxacin and moxifloxacin) can be used to treat $M$. pneumoniae infections as an alternative to macrolides when clinically relevant [19], however, their use in children is limited due to effects on bone toxicity and cartilage development, respectively $[20,21]$.

We did not isolate $M$. pneumoniae by culture from those specimens wherein $M$. pneumoniae was detected by PCR and therefore we were not able to confirm phenotypic macrolide resistance. However, point mutations within the 23SrRNA gene in clinical specimens and isolates, including the $\mathrm{A} 2058 \mathrm{G}$ mutation, have previously been shown to confer resistance [16]. Acquisition of resistance has been documented in patients receiving macrolides and resistance may develop as a consequence of antibiotic selective pressure [22]. This is supported by the highest macrolide resistance rates being reported in countries with extensive macrolide use [15]. Increased vigilance pertaining to macrolideresistant $M$. pneumoniae in the UK is recommended. 


\section{Acknowledgements}

The authors are grateful to $G$ Dabrera, $T$ Harrison and $M$ Chand, Public Health England, for critical reading of the manuscript and to C Morley, B Mistry and F Andrewartha for assistance in collating data.

\section{Conflict of interest}

None declared.

\section{Authors' contributions}

RJB wrote the manuscript, LMS undertook PCR and local study conception, SP performed macrolide resistance analysis, VJC designed, oversaw the study and wrote the manuscript.

\section{References}

1. Chalker VJ, Stocki T, Mentasti M, Harnden A, Wang K, Harrison TG. Macrolide resistant Mycoplasma pneumoniae in England and Wales: Abstract $\mathrm{P} 724,22 \mathrm{nd}$ European Congress of Clinical Microbiology and Infectious Diseases.Clin Microbiol Infect. 2012;18(S3):135.

2. Ferguson GD, Gadsby NJ, Henderson SS, Hardie A, Kalima P, Morris AC, et al. Clinical outcomes and macrolide resistance in Mycoplasma pneumoniae infection in Scotland, UK. J Med Microbiol. 2013;62(Pt 12):1876-82. .DOI: 10.1099/ jmm.0.066191-o PMID: 24008501

3. Li X, Atkinson TP, Hagood J, Makris C, Duffy LB, Waites KB. Emerging macrolide resistance in Mycoplasma pneumoniae in children: detection and characterization of resistant isolates.Pediatr Infect Dis J. 2009;28(8):693-6. .DOI: 10.1097/ INF.obo13e31819e3f7a PMID: 19633515

4. Wang K, Chalker V, Bermingham A, Harrison T, Mant D, Harnden A. Mycoplasma pneumoniae and respiratory virus infections in children with persistent cough in England: a retrospective analysis.Pediatr Infect Dis J. 2011;30(12):1047-51. .DOI: 10.1097/INF.ob013e31822db5e2 PMID: 21857262

5. Narita M. Pathogenesis of extrapulmonary manifestations of Mycoplasma pneumoniae infection with special reference to pneumonia.J Infect Chemother. 2010;16(3):162-9. .DOI: 10.1007/S10156-010-0044-X PMID: 20186455

6. Bitnun A, Ford-Jones E, Blaser S, Richardson S. Mycoplasma pneumoniae ecephalitis. Semin Pediatr Infect Dis. 2003;14(2):96-107. .DOI: 10.1053/spid.2003.127226 PMID: 12881797

7. Olson D, Watkins LK, Demirjian A, Lin X, Robinson CC, Pretty $\mathrm{K}$, et al. Outbreak of Mycoplasma pneumoniae-Associated Stevens-Johnson Syndrome. Pediatrics. 2015;136(2):e386-94. .DOI: $10.1542 /$ peds.2015-0278 PMID: 26216320

8. Gu L, Chen X, Li H, Qu J, Miao M, Zhou F, et al. A case of lethal hemolytic anemia associated with severe pneumonia caused by Mycoplasma pneumoniae. Chin Med J (Engl). 2014;127(21):3839.PMID: 25382347

9. Chalker VJ, Stocki T, Mentasti M, Fleming D, Sadler C, Ellis J, et al. Mycoplasma pneumoniae infection in primary care investigated by real-time PCR in England and Wales. Eur J Clin Microbiol Infect Dis. 2011;30(7):915-21. .DOI: $10.1007 /$ s10096 011-1176-3 PMID: 21311941

10. Spuesens EB, Fraaij PL, Visser EG, Hoogenboezem T, Hop WC, van Adrichem LN, et al. Carriage of Mycoplasma pneumoniae in the upper respiratory tract of symptomatic and asymptomatic children: an observational study. PLoS Med. 2013;10(5):e1001444. .DOI: 10.1371/journal.pmed.1001444 PMID: 23690754

11. European Working Group on Mycoplasma pneumoniae surveillance,Lenglet A, Herrador Z, Magiorakos AP, Leitmeyer $K$, Coulombier D. Surveillance status and recent data for Mycoplasma pneumoniae infections in the European Union and European Economic Area, January 2012.Euro Surveill. 2012;17(5):20075.PMID: 22321134

12. Bébéar C. Editorial commentary: infections due to macrolideresistant Mycoplasma pneumoniae: now what?Clin Infect Dis. 2012;55(12):1650-1. .DOI: 10.1093/cid/cis791 PMID: 22972858

13. Zhao F, Liu G, Wu J, Cao B, Tao X, He L, et al. Surveillance of macrolide-resistant Mycoplasma pneumoniae in Beijing, China, from 2008 to 2012. Antimicrob Agents Chemother.
2013;57(3):1521-3. .DOI: 10.1128/AAC.02060-12 PMID: 23263003

14. Principi N, Esposito S. Macrolide-resistant Mycoplasma pneumoniae: its role in respiratory infection.j Antimicrob Chemother. 2013;68(3):506-11. .DOI: 10.1093/jac/dks457 PMID: 23169891

15. Bébéar C, Pereyre S, Peuchant O. Mycoplasma pneumoniae: susceptibility and resistance to antibiotics. Future Microbiol. 2011;6(4):423-31. .DOI: 10.2217/fmb.11.18 PMID: 21526943

16. Bébéar CM, Pereyre $S$. Mechanisms of drug resistance in Mycoplasma pneumoniae.Curr Drug Targets Infect Disord. 2005;5(3):263-71. .DOI: 10.2174/1568005054880109 PMID: 16181145

17. British Thoracic Society Standards of Care Committee,Harris M, Clark J, Coote N, Fletcher P, Harnden A, McKean M, et al. . British Thoracic Society guidelines for the management of community acquired pneumonia in children: update 2011.Thorax. 2011;66(Suppl 2):ii1-23. .DOI: 10.1136/ thoraxjnl-2011-200598 PMID: 21903691

18. Lim WS, Baudouin SV, George RC, Hill AT, Jamieson C, Le Jeune I, et al. BTS guidelines for the management of community acquired pneumonia in adults: update 2009. Thorax. 2009;64(S3):pii:1-55.

19. Bebear C, Kempf I. Antimicrobial therapy and antimicrobial resistance. In Blanchard A, Browning G, editors. Mycoplasmas: Pathogenesis, Molecular Biology, and Emerging Strategies for Control. Horizon Bioscience: Wymondham, UK; 2005.

20. Rao RP, Ghanayem NS, Kaufman BA, Kehl KS, Gregg DC, Chusid MJ. Mycoplasma hominis and Ureaplasma species brain abscess in a neonate.Pediatr Infect Dis J. 2002;21(11):1083-5. .DOI: 10.1097/00006454-200211000-00026 PMID: 12458575

21. Pediatric Infectious Diseases Society and the Infectious Diseases Society of America,Bradley JS, Byington CL, Shah $\mathrm{SS}$, Alverson B, Carter ER, Harrison C, et al. . The management of community-acquired pneumonia in infants and children older than 3 months of age: clinical practice guidelines by the Pediatric Infectious Diseases Society and the Infectious Diseases Society of America.Clin Infect Dis. 2011;53(7):e25-76. .DOI: 10.1093/cid/cir531 PMID: 21880587

22. Cardinale $F$, Chironna $M$, Dumke R, Binetti $A$, Daleno C, Sallustio A, et al. Macrolide-resistant Mycoplasma pneumoniae in paediatric pneumonia. Eur Respir J. 2011;37(6):1522-4. .DOI: 10.1183/09031936.00172510 PMID: 21632830 